\title{
Mediastinal Neuroblastoma
}

National Cancer Institute

\section{Source}

National Cancer Institute. Mediastinal Neuroblastoma. NCI Thesaurus. Code C6628.

A neuroblastoma arising from the mediastinum. 